\title{
Recovery of the Critically Endangered bracket fungus Amylocystis lapponica in the Estonian network of strictly protected forests
}

\author{
Kadri RUnNel, IndRek SELL and ASko Lõhmus
}

\begin{abstract}
In regions where primeval forests have vanished it is unclear whether forest protection can sustain specialized old-forest biota, and over what time scale. We report on population expansion of an old-growth specific fungus of European conservation concern, Amylocystis lapponica, in the forest reserve network of Estonia. This conspicuous species was known for 40 years from only single records in one old-growth forest and was categorized nationally as Critically Endangered. During the last 10 years A. lapponica has expanded over the eastern half of the country, with nine subpopulations, in 12 localities, now known, all in longprotected old-growth forests and several $>50 \mathrm{~km}$ apart. In most of the new localities historical absence of the species can be reliably assessed based on earlier surveys. The historical remnant subpopulation has also increased. The population size (c. 100 mature individuals) in Estonia indicates the species should be recategorized nationally as Endangered. This success story suggests that more than 50 years of non-intervention may be needed even in large old-forest reserves for old-growth specialist species to recover.
\end{abstract}

Keywords Amylocystis lapponica, bracket fungus, forest, fungal conservation, old growth, Picea abies, refuge population, succession

Supplementary material for this article is available at https://doi.org/10.1017/So030605319000334

Tn many developed countries a major conservation 1 challenge is to sustain old-forest biota despite historical loss of natural forests. Most European countries retain $<1 \%$ of their primary forest (Sabatini et al., 2018) and reserves already cover $>12 \%$ of current forest area (Forest Europe, 2015). In degraded forests many old-forest specialist species may not be viable and will be extirpated unless their habitat is restored (Hanski, 2000). The global Aichi Biodiversity

KADRI RUNNEL (Corresponding author, (c) orcid.org/0000-0002-7308-3623) Department of Zoology, Institute of Ecology and Earth Sciences, University of Tartu, Vanemuise 46, EE-51014 Tartu, Estonia. E-mail kadri.runnel@ut.ee

INDREK Sell MTÜ Puuseen, Tartu, Estonia

Asко Löнмus Department of Zoology, Institute of Ecology and Earth Sciences, University of Tartu, Tartu, Estonia

Received o9 January 2019. Revision requested 12 February 2019.

Accepted 10 April 2019. First published online 19 September 2019.
Targets (Convention on Biological Diversity, 2010) provide political support to improve this situation by further expanding reserve networks, restoring degraded ecosystems, and preventing species extinctions. However, the targets do not specify how to combine conservation options in practice (e.g. Jørgensen, 2013; Venter et al., 2014).

A central management problem in historically degraded, but now protected forests is that old-growth qualities develop slowly, and the prospects for old-forest biota depend on unpredictable colonization and extirpation processes. In most countries protected forest networks have existed for only a few decades and thus have limited structural recovery (e.g. Meyer \& Schmidt, 2011; Paillet et al., 2015; Bujoczek et al., 2018). There is some evidence of broad-scale recovery of species with moderate old-forest associations within a few decades of the protection of secondary forests (e.g. Vandekerkhove et al., 2012; Deinet et al., 2013; Romero et al., 2013), but such recoveries depend on species' life history traits, location of source populations, and dispersal capabilities (Sverdrup-Thygeson et al., 2014). Non-intervention management has also enabled a disturbance-phase specialist fungus to spread across large naturally disturbed areas (Bässler \& Müller, 2010). However, for the most demanding old-forest species broad-scale recoveries attributable to reserve network initiatives have not been described.

Here, we report on population expansion of an oldgrowth specific fungus Amylocystis lapponica (Agaricomycetes, Polyporales, Polyporaceae) in the forest reserve network of Estonia. Although its preliminary global Red List status is Least Concern (IUCN, 2018), in Europe it is one of the 33 threatened fungi recommended for listing in the Bern Convention (Dahlberg \& Croneborg, 2003). In the last 30 years this species has been recorded in eight European countries, with the majority of the population in the boreal zone. Outside the boreal zone, this species is only present in a few refugia in the best-preserved Central European primeval forests (Holec \& Kučera, 2007). In Estonia (the hemiboreal zone) A. lapponica was known for 40 years from a single old-growth patch (Parmasto, 2004), has been categorized as Critically Endangered since 1998, when first assessed (Lilleleht, 1998; Lõhmus et al., 2018b), and is legally protected.

Forests currently cover $51 \%$ of Estonia's $45,228 \mathrm{~km}^{2}$ land area but old natural stands cover only $1 \%\left(<500 \mathrm{~km}^{2}\right)$, over half of which is in reserves (Raudsaar et al., 2018). Before significant spread of agriculture, c. 3000 BCE, forest cover was 
probably at least $85 \%$; spruce forests are a major ecosystem of the east and south (Laasimer, 1965). At least $21 \%$ of land has remained long-term forest (although repeatedly logged), and other forests are either 2oth century reforestations (various types of agricultural lands) or new forests on drained wetlands.

In the second half of the 2oth century most Estonian forests were managed with a medium-intensity semi-natural approach, which maintained tree species diversity and relatively high volumes of dead wood. As a consequence, many generalist old-forest species could inhabit production forests (e.g. Lõhmus et al., 2016; Runnel \& Lõhmus, 2017). Nevertheless, several highly specialized species, including A. lapponica and other fungi of spruce-dominated forests, remain highly threatened in protected old-forests or have already become regionally extinct (Runnel \& Lõhmus, 2017; Lõhmus et al., 2018b).

The Estonian network of strictly protected forests developed slowly from 1924 until the 1990s, without central planning (Tuvi et al., 2011). Later focused developments include designation of Natura 2000 sites of European importance and, nationally, targeting minimum areas for old-growth forest species in each forest type (Lõhmus et al., 2004). The area of strictly protected forests increased from c. $3 \%$ of forest land in the early 1990 s to $6 \%$ in 2001 and $13 \%$ by 2018 (Lõhmus et al., 2004; Raudsaar et al., 2018). However, reflecting general forest history, few of the strictly protected sites include any primeval forest and $>50 \%$ of their total area will still be $<100$ years old by 2030 (Lõhmus, 2016). Recently intensified timber harvesting has fragmented the landscapes and isolated the strictly protected sites (Forest Europe, 2015; Lõhmus, 2016).

The A. lapponica material we analysed is based on fruitbody records from three main sources, and survey histories in these localities to evaluate historical absences (Supplementary Material 1). (1) All casual collections of Estonian polypores are documented in public database Plutof (Abarenkov et al., 2010). Polypores have been well surveyed since the 1950 in Estonian forests, with emphasis on old forests and rare species. Parmasto (2004) published all material up to 2004 ( $>13,000$ records), mostly collected by professional mycologists. Later data include increasing contributions from amateur mycologists, national monitoring activities, and results of fungal surveys in several protected forest areas. (2) Over 20,000 polypore records originate from c. 180 systematic stand-scale surveys during 2005-2018, representing the main forest types and stages of forest age and naturalness. The survey method detects local species pools and also documents species absences (Lõhmus et al., 2018a). This dataset has been instrumental in assessing the national conservation status of polypores (Runnel \& Lõhmus, 2017; Lõhmus et al., 2018b). (3) A. lapponica is the most strictly protected (Category I) species under the national Nature Conservation Act, and its confirmed and potential localities have been monitored by IS during 2008-2018. The fruit bodies of A. lapponica are easily detectable when mature and fresh (Lõhmus, 2009), but parts of juvenile or old fruit bodies that could not be reliably identified have been collected for microscopy. Substrate descriptions of the records were made on-site, but stand characteristics are reported according to the National Forest Registry (based on geographical coordinates of the records).

The synthesis of these datasets reveals a recent expansion of A. lapponica from a single forest reserve to other longprotected parts of the national network of protected forests. Its fruit bodies were first discovered in eastern Estonia in 1969, in a 19-ha old-growth patch, protected since 1924 (the first Estonian forest reserve) and surveyed by mycologists since the 1930s. Despite frequent visits to this reserve, the species was re-recorded on a single trunk only in 1991, 2001, 2006 and 2008. The findings became annual from 2010 (three records), and with 10 records in 2018, the species had spread over most of the reserve.

During 2011-2018 there were a total of 53 additional records. The number of known subpopulations (here defined as localities separated by $>5 \mathrm{~km}$ ) expanded to nine (Fig. 1); these include 12 separate localities (contiguous forest areas with records typically $<_{1} \mathrm{~km}$ and no more than $3 \mathrm{~km}$ apart). In 2011 two records were made in Muraka nature reserve (north-eastern Estonia), which is probably the largest surviving primeval spruce forest in the country (officially protected since 1959; surveyed by mycologists since the 1960s). In 2016 another locality $2.8 \mathrm{~km}$ away and another subpopulation $7 \mathrm{~km}$ away were discovered. In 2017, two new subpopulations were found elsewhere in Estonia: in Alam-Pedja Nature Reserve in east-central Estonia (de facto protected since 1948 when it became a Soviet military area) and in old-growth stands in Karula National Park, southern Estonia (officially protected since 1979). There were a total of 22 records in 2018, all in long-protected forests and most in previously surveyed areas (Supplementary Material 1). These records included four additional subpopulations, all to the west of previously known records, and thus the species' known western range in Estonia has shifted from $27^{\circ} \mathrm{E}$ in 2011 to $25^{\circ} \mathrm{E}$ in 2018.

All fruit bodies were found on medium to well-decayed downed Norway spruce Picea abies trunks (diameter at breast height $28-61 \mathrm{~cm}$ ). The 34 forest stands inhabited were either mesic to eutrophic highly productive stands on mineral soil (25 stands; site types ranging from OxalisRhodococcum to Aegopodium) or old drained peatland forests ( 9 stands). Their common feature was a developed old-growth structure, with variable coverage of spruce in the overstorey $(5-86 \%)$. Six stands had a dominant tree layer $<100$ years old; this was a result of natural succession after historical disturbance or natural replacement of oldgrowth spruce forest with nemoral broad-leaved trees. 


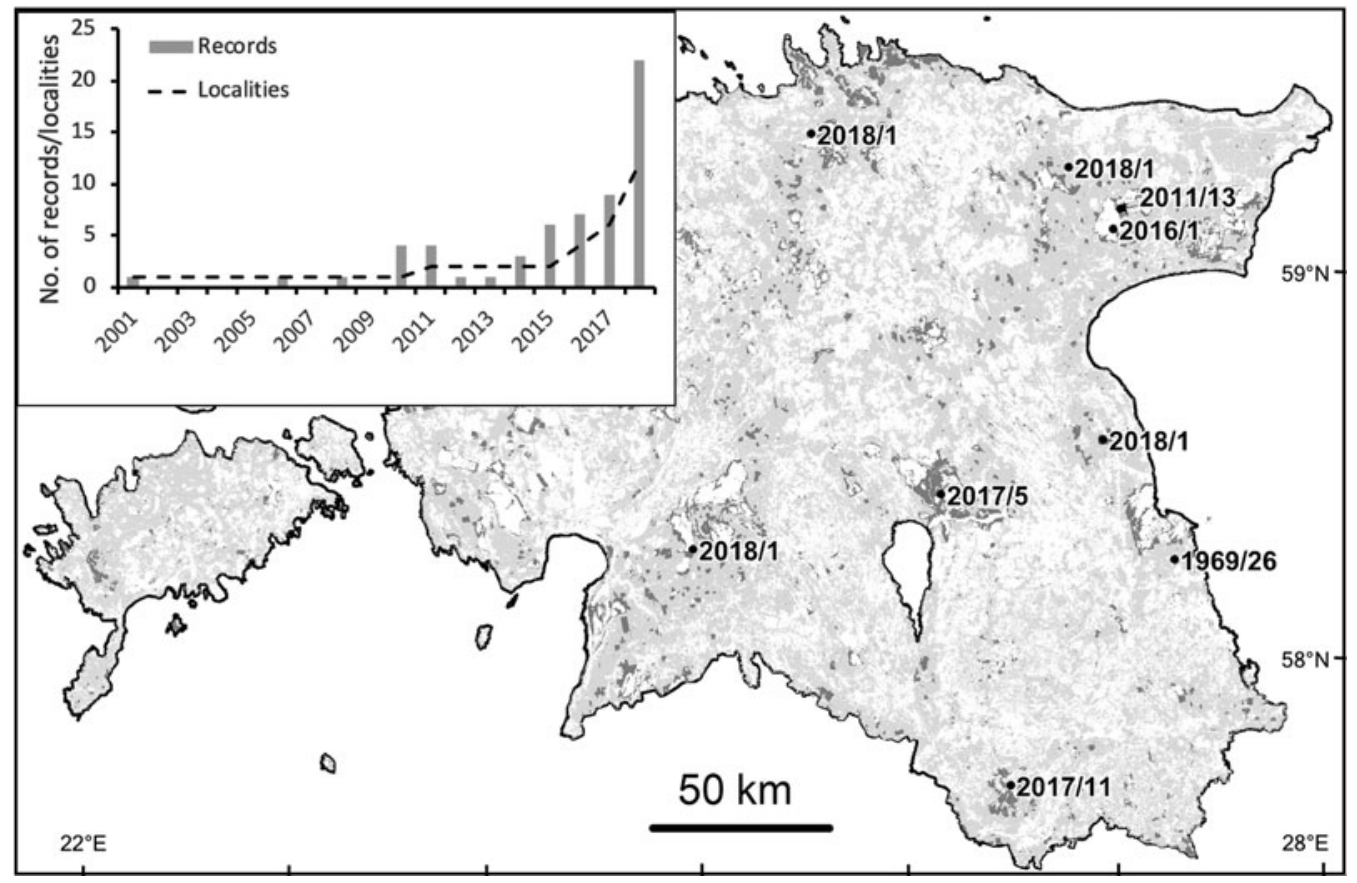

FIG. 1 Distribution of Amylocystis lapponica subpopulations in Estonia (discovery year/total no. of records). Light grey indicates forests, dark grey indicates strictly protected forests. The graph shows the annual number of records and cumulative no. of known localities, 2001-2018.

Based on annual maximum numbers of recent records, we estimate that $A$. lapponica currently inhabits $>50$ spruce trunks in the 12 known Estonian localities, with c. 100 mature individuals (Dahlberg \& Mueller, 2011). It should thus be categorized nationally as Endangered under criterion D, based on population size (IUCN, 2001). Given the adequate protection of existing localities and the population increase observed, the species has potential to improve nationally to Vulnerable (in terms of population size). However, the records also confirm the species' strict requirements for longdeveloped natural forest (Dahlberg \& Croneborg, 2003; Holec \& Kučera, 2007; Nordén et al., 2018). Such habitats have almost vanished outside strictly protected forests and the improving status of $A$. lapponica depends on a network of such forests. Given the long history of spruce-dominated old-growth ecosystems in Estonia (Reitalu et al., 2013), it is thus plausible that $A$. lapponica passed a population bottleneck in Estonia during the unprecedented forest loss of the first half of the 2oth century (e.g. Meikar \& Etverk, 2000). However, there are no mycological records available to attest to its status in preceding centuries.

We highlight the data quality of our assessment, which includes long-term monitoring in key locations, systematic surveys, and the availability of all historical data. Specifically, we used the significance of the species to assess absences based on site visits: iconic species are likely to be reported whenever specialists visit the sites (see also Halme et al., 2012), and documentation of all records of this species is legally required in Estonia. Frequent visits are, however, more likely to attractive habitats (in this case old-growth forests); to confirm that such visiting bias (cf. Lõhmus \& Lõhmus, 2009) did not undermine documentation of the actual distribution of A. lapponica, we used a separate sampling scheme representing less attractive habitats (e.g. younger forests; Runnel \& Lõhmus, 2017). Despite careful synthesis of multiple data sources, only one location was known for the first 50 years of the survey history and the expansion of records was not related to parallel expansion of site visits.

The qualities of the Estonian strictly protected forest network that have supported A. lapponica require study. The network's extent facilitated the species' range expansion (Fig. 1) and the presence of old-growth forest was needed for formation of local populations that could act as future sources, but we cannot yet explain the historical absences of A. lapponica in those patches and the species' relatively rapid spread. We suggest, however, that the explanation lies in the dramatic socio-economic changes in forest management in the 1940s, which reversed forest loss (increasing landscape connectivity; cf. Penttilä et al., 2006), and reduced timber harvesting and local forest use (e.g. Tomson et al., 2015). Several localities appear to have become de facto protected during this time, even if forest reserves and the networks for strictly protected forests were only established later. Thus, habitat development for A. lapponica may require $>50$ years of non-intervention even in old stands. The exact reasons for such long time delay, opportunities for active habitat restoration, and the role of dispersal sources are unknown. At least in north-east Estonia, 
there may have been eastern cross-border colonization, but the recent accelerated spread of the species (Fig. 1) indicates an increasing role of local dispersal. Our findings indicate that, for fungi, the merits of non-intervention management regimes and large strictly protected forest networks may become evident only in the long term, and therefore research on such species requires a combination of species indicators, monitoring schemes and historical data.

Acknowledgements Long-term data on Estonian forest fungi have been collected by many local and visiting mycologists. We specifically thank Urmas Ojango for his records from north-east Estonia. Financial support to KR and AL was provided by the Estonian Research Council (grant IUT 34-7). IS has been financed by the Estonian Environmental Agency and Environmental Board (national programme for monitoring biodiversity and landscapes, during 2008-2018) and the Environmental Investment Centre (mycological surveys in various conservation areas during 2015-2018). We thank Agu Leivits for commenting on the text, and two anonymous reviewers for their constructive comments. Collecting was permitted by the Estonian Environmental Board (permit no. 1-1/16/354 for sampling protected species); all collected material is stored in the fungal collections TAAM and TU.

Author contributions Study design and fieldwork: KR, IS, AL; data analysis and writing: KR, AL.

\section{Conflicts of interest None.}

Ethical standards The research complies with the Oryx guidelines on ethical standards and was carried out following Estonian laws for handling protected species.

\section{References}

Abarenkov, K., Tedersoo, L., Nilsson, R.H., Vellak, K., SaAr, I., Veldre, V. et al. (2010) PlutoF-a web based workbench for ecological and taxonomic research, with an online implementation for fungal ITS sequences. Evolutionary Bioinformatics, 6, EBOS6271.

BÄSSLER, C. \& MÜLLER, J. (2010) Importance of natural disturbance for recovery of the rare polypore Antrodiella citrinella Niemelä \& Ryvarden. Fungal Biology, 114, 129-133.

Bujoczek, L., Szewczy , J. \& Bujoczek, M. (2018) Deadwood volume in strictly protected, natural, and primeval forests in Poland. European Journal of Forest Research, 137, 401-418.

Convention on Biological Diversity (2010) COP Decision X/2. Strategic Plan for Biodiversity 2011-2020. Http://www.cbd.int/ decision/cop/?id=12268 [accessed 1 November 2018].

Dahlberg, A. \& Croneborg, H. (2003) The 33 Threatened Fungi in Europe-Complementary and Revised Information on Candidates for Listing in Appendix I of the Bern Convention. Swedish Species Information Centre, Uppsala, Sweden.

Dahlberg, A. \& Mueller, G.M. (2011) Applying IUCN red-listing criteria for assessing and reporting on the conservation status of fungal species. Fungal Ecology, 4, 147-162.

Deinet, S., Ieronymidou, C., McRae, L., Burfield, I.J., Foppen, R.P., Collen, B. \& Böнm, M. (2013) Wildlife Comeback in Europe: the Recovery of Selected Mammal and Bird Species. Final Report to Rewilding Europe by Zoological Society of London, BirdLife
International and the European Bird Census Council. Zoological Society of London, London, UK.

Forest Europe (2015) State of Europe's Forests 2015. Ministerial Conference on the Protection of Forests in Europe, Madrid, Spain.

Halme, P., Heilmann-Clausen, J., Rämä, T., Kosonen, T. \& KuntTU, P. (2012) Monitoring fungal biodiversity-towards an integrated approach. Fungal Ecology, 5, 750-758.

HANSKI, I. (2000) Extinction debt and species credit in boreal forests: modelling the consequences of different approaches to biodiversity conservation. Annales Zoologici Fennici, 37, 271-280.

Holec, J. \& KuČera, T. (2007) Remarks to the ecology of the boreo-montane polypore Amylocystis lapponica based on data from the Czech Republic and Poland. Acta Mycologica, 42, 161-168.

IUCN (2001) IUCN Red List Categories and Criteria: Version 3.1. IUCN Species Survival Commission, IUCN, Gland, Switzerland.

IUCN (2018) List of Preliminary Assessed Fungal Species. IUCN Global Fungal Red List Initiative. http://iucn.ekoo.se/iucn/species_list/ \#tab-species-list-thumbs-assessment-prel [accessed 5 November 2018].

JørGensen, D. (2013) Ecological restoration in the Convention on Biological Diversity targets. Biodiversity and Conservation, 22, 2977-2982.

Laasimer, L. (1965) Vegetation of the Estonian SSR. Valgus, Tallinn, Estonia.

Lilleleht, V. (1998) Red Data Book of Estonia: Threatened Plants, Fungi and Animals. Eesti Teaduste Akadeemia Looduskaitse Komisjon, Tartu, Estonia.

LõHmus, A. (2009) Factors of species-specific detectability in conservation assessments of poorly studied taxa: the case of polypore fungi. Biological Conservation, 142, 2792-2796.

Lõ hmus, A. (2016) Eesti Rangelt Kaitstavate Metsade Tüpoloogiline Analü̈̈s [Typological Analysis of Estonian Strictly Protected Forests]. Ministry of the Environment, Tallinn, Estonia. Https://www.envir. ee/sites/default/files/metsade_range_kaitse_2016_alohmus.pdf [accessed 3 October 2018].

Löhmus, A., Kohv, K., Palo, A. \& Villma, K. (2004) Loss of old-growth, and the minimum need for strictly protected forests in Estonia. Ecological Bulletins, 51, 401-411.

Lõhmus, P. \& Lõhmus, A. (2009) The importance of representative inventories for lichen conservation assessments: the case of Cladonia norvegica and C. parasitica. The Lichenologist, 41, 61-67.

Lõhmus, A., Lõhmus, P. \& Runnel, K. (2018a) A simple survey protocol for assessing terrestrial biodiversity in a broad range of ecosystems. PLOS ONE, 13, eo208535.

Lõhmus, A., Nellis, R., Pullerits, M. \& Leivits, M. (2016) The potential for long-term sustainability in seminatural forestry: a broad perspective based on woodpecker populations. Environmental Management, 57, 558-571.

Lõhmus, A., Vunk, E. \& Runnel, K. (2018b) Conservation management for forest fungi in Estonia: the case of polypores. Folia Cryptogamica Estonica, 55, 79-89.

Meikar, T. \& Etverk, I. (200o) Forest ownership in Estonia. Metsanduslikud uurimused, 32, 8-18.

Meyer, P. \& Schmidt, M. (2011) Accumulation of dead wood in abandoned beech (Fagus sylvatica L.) forests in northwestern Germany. Forest Ecology and Management, 261, 342-352.

Nordén, J., Åström, J., Josefsson, T., Blumentrath, S., Ovaskainen, O., Sverdrup-Thygeson, A. \& Nordén, B. (2018) At which spatial and temporal scales can fungi indicate habitat connectivity? Ecological Indicators, 91, 138-148.

Paillet, Y., Pernot, C., Boulanger, V., Debaive, N., Fuhr, M., Gilg, O. \& Gosselin, F. (2015) Quantifying the recovery of old-growth attributes in forest reserves: a first reference for France. Forest Ecology and Management, 346, 51-64. 
Parmasto, E. (2004) Distribution Maps of Estonian Fungi. III. Pore Fungi. Institute of Zoology and Botany of the Estonian Agricultural University, Tartu, Estonia.

Penttilä, R., Lindgren, M., Miettinen, O., Rita, H. \& Hanski, I. (2006) Consequences of forest fragmentation for polyporous fungi at two spatial scales. Oikos, 114, 225-240.

Raudsaar, M., Simmon, K-L. \& Valgepea, M. (2018) Yearbook Forest 2017. Estonian Environmental Agency, Tallinn, Estonia.

Reitalu, T., Seppä, H., Sugita, S., Kangur, M., Koff, T., Avel, E. et al. (2013) Long-term drivers of forest composition in a boreonemoral region: the relative importance of climate and human impact. Journal of Biogeography, 40, 1524-1534.

Romero, J.L.R., Lammertink, M. \& Cañestro, J.P. (2013) Population increase and habitat use of the middle spotted woodpecker Dendrocopos medius in the Aran Valley, Spanish Pyrenees. Ardeola, 6o, 345-355.

Runnel, K. \& Lõhmus, A. (2017) Deadwood-rich managed forests provide insights into the old-forest association of polypores. Fungal Ecology, 27, 155-167.

Sabatini, F.M., Burrascano, S., Keeton, W.S., Levers, C., Lindner, M., Pötzschner, F. et al. (2018) Where are Europe's last primary forests? Diversity and Distributions, 24, 1426-1439.
Sverdrup-Thygeson, A., Bendiksen, E., Birkemoe, T. \& Larsson, K.H. (2014) Do conservation measures in forest work? A comparison of three area-based conservation tools for wood-living species in boreal forests. Forest Ecology and Management, 330, 8-16.

Tomson, P., Bunce, R.G.H. \& Sepp, K. (2015) The role of slash and burn cultivation in the formation of southern Estonian landscapes and implications for nature conservation. Landscape and Urban Planning, 137, 54-63.

Tuvi, E.L., Vellak, A., Reier, Ü., Szava-Kovats, R. \& Pärtel, M. (2011) Establishment of protected areas in different ecoregions, ecosystems, and diversity hotspots under successive political systems. Biological Conservation, 144, 1726-1732.

Vandekerkhove, K., De Keersmaeker, L., Walleyn, R., Köhler, F., Crevecoeur, L., Govaere, L. et al. (2012) Reappearance of old growth elements in lowland woodlands in northern Belgium: do the associated species follow? Silva Fennica, 45, 909-935.

Venter, O., Fuller, R.A., Segan, D.B., Carwardine, J., Brooks, T., Butchart, S.H. et al. (2014) Targeting global protected area expansion for imperiled biodiversity. PLOS Biology, 12, e1001891. 